\title{
Solving Closed-loop Supply Chain Problems using Game Theoretic Particle Swarm Optimisation
}

\begin{abstract}
In this paper, we propose a closed-loop supply chain network configuration model and a solution methodology that aims to address several research gaps in the literature. The proposed solution methodology employs a novel metaheuristic algorithm, along with the popular gradient descent search method, to aid location-allocation and pricing-inventory decisions in a two-stage process. In the first stage, we use an improved version of the particle swarm optimisation (PSO) algorithm, which we call improved PSO (IPSO), to solve the locationallocation problem. The IPSO algorithm is developed by introducing mutation to avoid premature convergence and embedding an evolutionary game-based procedure known as replicator dynamics to increase the rate of convergence. The results obtained through the application of IPSO are used as input in the second stage to solve the inventory-pricing problem. In this stage, we use the gradient descent search method to determine the selling price of new products and the buy-back price of returned products, as well as inventory cycle times for both product types. Numerical evaluations undertaken using problem instances of different scales confirm that the proposed IPSO algorithm performs better than the comparable traditional PSO, simulated annealing and genetic algorithm methods.
\end{abstract}

Key Words: closed loop supply chain, particle swarm optimisation, optimisation, facility location, inventory management

\section{Introduction}

With the prominence accorded to environmental sustainability and social responsibility by multiple stakeholder groups, closed-loop supply chain management (CLSCM) has increasingly attracted the attention of researchers over the past two decades (Dutta et al., 2016; Govindan et al., 2015). People, in general, have become more conscious and cautious of the consequences of environmental degradation (Dowlatshahi, 2000) and have responded positively towards initiatives that focus on efficient use of resources (Shukla and Kiridena, 2016) and safe disposal of end-of-life products. Many countries have adopted stringent legislation aimed at strengthening measures of product stewardship, thereby forcing businesses to take back used products and reduce waste generated through their operations (Kumar and Putnam, 2008). Endof-life products that would otherwise go to waste can, in effect, have some remaining value in terms of reducing the consumption of raw materials, and decreasing waste production and the costs of disposal (Meng et al., 2016; Faccio et al., 2014; Guide Jr. and Wassenhove, 2009). As such, businesses can derive benefits from initiatives that incorporate reverse logistics (RL) activities into supply chains. Such activities can reduce input costs through the re-use and recovery of products, and increase revenue through the enhancement of brand image (Dubey et al., 2015; Hong et al., 2015; Atasu et al., 2008). Given that the business value of CLSCM is now well-established, there are opportunities for operationalising the concept through focused research. 
To this end, there is currently a substantial body of CLSCM literature to draw upon. Based on a comprehensive and systematic review of 382 papers, Govindan and colleagues (2015) provide a detailed account of future research directions. Other significant review articles we have been able to locate in the CLSCM literature include Govindan and Soleimani (2017); Souza (2013); Guide Jr. and Wassenhove (2009); Akcali and Uster (2008); and Jayaraman et al. (2003). In this paper, we draw on these review articles and other recent work to determine the scope of our study and to develop a suitable modelling approach and solution methodology.

First, in setting the scope, we adopt the integrated forward-reverse network out of the three main alternative closed-loop supply chain (CLSC) network configurations used in extant literature. Our choice was made based on several considerations drawn from the literature, such as minimisation of overall logistics costs, maximisation of asset utilisation and leverage of established channel relationships (Kaya and Ureck, 2016; De Giovanni and Zaccour, 2014).

Second, in response to calls for the integration of decision variables at multiple levels, we address a number of strategic, tactical and operational decisions collectively in this study (see Figure 1). We focus on key strategic-tactical decisions such as the location of facilities and the allocation of customer zones to those facilities, considering both market needs and transportation costs (Kaya and Ureck, 2016; Easwaran and Uster, 2010; Srivastava, 2008). We consider tactical-operational decisions such as the pricing policy (Esmaeili et al., 2016; Chen and Chang, 2013) and inventory cycle times (Asl-Najafi et al., 2015; Salema et al., 2010) while taking into account incentives offered for product returns.

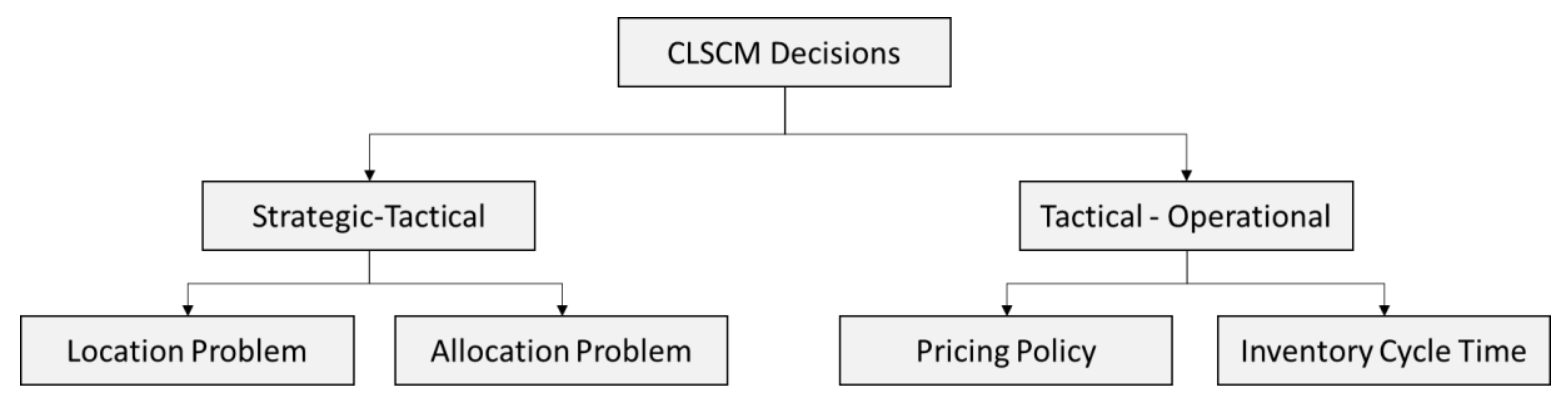

Fig. 1. The proposed problem structure

Third, in addition to the key decision variables referred to above, we incorporate several important parameters into our model in the form of logically derived values. These parameters were drawn from the literature, such as the number of facilities to be set up, the costs associated with setting up or operating those facilities, and the capacity of such facilities (Ahmadzadeh and Vahdani, 2017; Kaya and Urek, 2016; Dai and Zheng, 2015; Amin and Zhang, 2013). In so doing, we aim to address the trade-off between the veracity of the model and computational challenges.

In dealing with strategic-tactical decisions, we employed a modified form of the evolutionary algorithm-based particle swarm optimisation (PSO). This modified PSO, which we refer to as improved particle swarm optimisation (IPSO), is used to locate retailers to reduce the 
transportation distance and/or travel time required for moving goods between network nodes. Once the retailers are located, we employ an allocation schema to determine which customer zone is to be served by which retailer. Based on the location-allocation results obtained, we derive some parameters concerning relevant CLSC network attributes, like the capacity level of retailers, cost of ordering from each retailer, and the establishment and operational costs of each retailer.

In dealing with tactical-operational decisions, we determine the appropriate selling and rebate prices, along with the volume of products that should be taken back from customers so as to maximise the manufacturer's profits. The volume of products returned depends on two factors: the incentives offered for product returns and the proximity of collection centres to customers. Furthermore, the level of incentive offered plays an important role in determining how to handle the trade-off between the revenue generated from a remanufactured product and the costs incurred in collecting it. Therefore, we aim to find the optimal sales price for products sold to consumers, while also considering the level of incentive offered. In determining the optimal inventory cycle time, we must consider that the retailer has to make re-orders in appropriate lot sizes at certain intervals to maintain stock levels that fully meet customer demands. Additionally, products collected from customers have to be returned to the manufacturer via retail outlets. As such, to minimise overall transport costs, the ordering cycle needs to be determined by considering the volumes of product moved in both directions. We use the values of selling price and rebate price derived in the previous step to calculate the retailer-specific optimal ordering frequency using the standard economic order quantity (EOQ) formula (Maddah \& Jabber, 2008).

A detailed evaluation of the results generated using the proposed model is undertaken to demonstrate the efficacy of IPSO in relation to other comparable algorithms. A number of scenarios are analysed by changing certain parameters, like the number of customer zones and retailers, to assess the scalability of our model. We discuss the outcomes generated using the proposed model so that relevant managerial insights can be drawn from our study.

The paper is organised as follows. Section 2 reviews the most relevant research, then we articulate the problem and its mathematical representation in Section 3. Our proposed solution methodology (IPSO) is presented in Section 4. Section 5 involves a numerical evaluation carried out using the proposed model to test its veracity. A detailed performance comparison of the IPSO with comparable algorithms is also included in this section. Section 6 concludes the paper with a brief account of its contributions, and directions for future research.

\section{Literature Review}

Various aspects of the CLSC configuration problem have been studied in the literature from multiple perspectives using a variety of modelling approaches and solution methods. The aspects of the CLSC configuration problem that have been widely studied include determining: the location of facilities, the capacity of facilities, prices, incentive levels, transport modes, vehicle routes, delivery schedules and inventory cycles. In the literature, these aspects have been categorised into strategic (design), tactical (planning) or operational decisions. 
Alternative perspectives from which these decisions have been studied include: minimisation of costs or maximisation of profits; optimisation of the flow of products across the network; mitigation of risk and uncertainty; and handling the scale and complexity of the network. The types of modelling approaches used in solving CLSCM problems have been classified as conceptual and mathematical, whereas the solution methods have been classified in terms of analytical and exact, approximation and heuristic, and meta-heuristic and other (Govindan et al., 2015).

Although significant progress has been made in terms of advancing knowledge in each of the decision areas referred to above, studies that simultaneously consider multiple decisions or integrate decisions at all three levels are limited (Govindan et al., 2015). A number of recent studies (e.g. Ahmadzadeh and Vahdani, 2017; Kaya and Urek, 2016; Asl-Najafi et al., 2015; Govindan et al., 2015) have highlighted the importance of integrating multiple decisions and considering multiple decision variables at all three levels in order to develop more effective supply network structures, as well as to achieve optimal network-level performance. These studies have also noted that such decisions have traditionally been considered separately, resulting in sub-optimal supply network-level performance. In this regard, a significant number of studies have simultaneously considered two decision variables while also accounting for uncertainty or scale (e.g. Dai and Zheng, 2015; Soleimani and Kannan, 2015; Asl-Najafi et al., 2015; Jindal and Sangwan, 2014; Nickel et al., 2012). However, studies that have considered more than two decision variables representing all three levels seem to be quite limited (Kaya and Ureck, 2016; Ahmadzadeh and Vahdani, 2017; Zhalechian et al., 2016). These studies will be further examined later in this section.

In terms of alternative perspectives from which various decisions have been studied, virtually all literature on CLSCM focuses on economic benefits; i.e. cost minimisation or profit maximisation in some form at the level of the network, entities or specific operations. Since the early calls for incorporating uncertainty into CLSCM studies were made, significant progress has been made in this area. We observed a large proportion of the more recent literature to have incorporated uncertainty and risk using stochastic approaches, fuzzy logic or interval programming (Govindan et al., 2015). Some studies have used various modelling approaches and solution methods to optimise the forward and reverse flows of products and material through networks (e.g. Vahdani and Mohammadi, 2015; Jindal and Sangwan, 2014).

In terms of the scale and complexity of CLSC networks, researchers have explored three forms of configuration. A number of studies have assumed a dedicated RL chain exclusively managed by the manufacturer to operate alongside the forward logistics chain (e.g. Amin and Zhang, 2013; Aras et al., 2008; Min et al., 2006; Jayaraman et al., 2003). In other studies, various forms of outsourcing in relation to RL operations, including inspections and sorting, refurbishing and disposal, have been considered (Genc and De Giovanni, 2017; De Giovanni and Zaccour, 2014; Kumar and Putnam, 2008). However, we observe increasing attention being given to using existing forward chain channel relationships for RL as well; under the oversight of the OEM with or without third party involvement (De Giovanni and Zaccour, 2014; Easwaran and Uster, 2010; Mutha and Pokharel, 2009; Fuente et al., 2008; Srivastava, 2008; Savaskan et al., 2004). Although many authors have discussed the merits and limitations 
of integrating forward and RL operations, some have more strenuously argued for integrated CLSCs (e.g. Kaya and Ureck, 2016). Additionally, a number of studies have also considered multi-product, multi-echelon or multi-period CLSC network configurations.

In summary, the above review suggests that there is a significant opportunity to contribute to the CLSCM literature by exploring multiple decision variables that represent the strategic, tactical and operational levels, while also accounting for other aspects such as green SC and sustainability. The literature also acknowledges the potential benefits of integrated CLSC networks; hence, there is a need to incorporate that aspect into future research. Further opportunities exist for testing models of more complex multi-product, multi-echelon configurations. However, consideration of complex, integrated CLSC network configurations that involve multiple decisions at all three levels poses significant challenges pertaining to the choice of modelling approaches and solution methodologies, as well as dealing with computational demands. For example, the need for efficient meta-heuristic algorithms and/or exact methods to deal with more complex CLSCM problems has been emphasised in several recent studies (Zhalechian et al., 2016; Kaya and Ureck, 2016; Asl-Najafi et al., 2015). Other authors have identified a need to explore the benefits of alternative approaches such as simulation-optimisation and other forms of simulation (Govindan and Soleimani, 2017; Pourhejazy and Kwon, 2017; Govindan et al., 2015). With these recommendations in mind, we now turn to examining the modelling approaches and solution methods used in extant CLSCM literature.

Several modelling approaches have been proposed in the literature to model the aspects of CLSCM referred to previously. However, linear and mixed integer linear programming (MILP) models have been predominantly used in this area (Govindan et al. 2015). Alumur and colleagues (2012) proposed an MILP formulation that incorporates reverse network structures and bills of materials for product returns, changes in the capacity of facilities, and multi-period, multi-commodity situations. Soleimani and Kannan (2015) proposed an MILP framework considering a multi-echelon, multi-product, multi-period scenario to address design and planning issues in a CLSC network. Soleimani and colleagues (2013) also introduced a model based on MILP to solve the location-allocation problem, which included parameters for nondeterministic demand and the prices of new and returned products, with expected profits as the overall objective function. Salema and colleagues (2007) proposed an MILP to include a CLSCM case where capacity limits, multi-product, and uncertain product demands and returns were considered. However, as there are multiple aspects in a typical CLSCM problem, nonlinear objectives and/or constraints are unavoidable. In recognition of this situation, Aras and Aksen (2008) developed a mixed-integer, non-linear, facility location-allocation model to optimally locate collection centres and determine the incentive levels that maximise profit from product returns. Overall, our review indicates that studies employing non-linear methods to model CLSCM decisions are rather limited.

In the field of CLSCM, various computational tools have been developed to address challenges such as those referred to above. In case of MILP-based models, for example, researchers have predominantly used analytical or exact methods (e.g. CPLEX, LINGO, GAMS) to solve smallscale problems. Chen (2011) proposed an analytical method to examine a situation involving a 
single-period CLSC model with demand uncertainty and product returns. Kannan et al. (2012) used LINGO to solve an MILP model that minimised a $\mathrm{CO}_{2}$ footprint while incorporating RL activities to recover used products. Listes (2007) proposed a branch-and-cut procedure for solving a CLSC design problem. When dealing with a problem of large dimensions, exact approaches for solving MILP models tend to suffer from computational difficulties. Therefore, alternative techniques, such as Benders decomposition method (Salema et al 2010) and metaheuristics (Govindan et al 2015), to solve larger-scale CLSCM problems have been called for in the literature.

Large-scale CLSCM problem instances have been solved using heuristic and metaheuristic methods such as genetic algorithms, simulated annealing and Tabu search. Kumar and Chan (2011) proposed a superiority search and optimisation metaheuristic for solving CLSCM problems, which included electronic tracking and environmental factors in multi-product, uncertain demand, and limited capacity settings. Meng et al. (2016) proposed an improved coevolutionary metaheuristic for green manufacturing by integrating a recovery option with disassembly planning for end-of-life products. Zhu and Xiuquan (2013) proposed a hybrid genetic algorithm for solving a SC formulation where uncertain selling, repairing and remanufacturing were considered. Schweiger and Sahamie (2013) proposed a hybrid Tabu search approach for designing a recycling network for paper-based products. Aras and Aksen (2008) proposed a heuristic procedure involving multi-level Tabu search-based nested loops to find a predetermined number of collection centres and the optimal financial incentive levels for different return types. Tiwari et al. (2016) used a hybrid of a distribution algorithm and a territory-defined multi-objective algorithm to select the optimum number of facilities in a CLSC. Lu and Bostel (2007) proposed an algorithm based on Lagrangian heuristics for a facility location problem with reverse flows. Other approaches based on simulation modelling (Chatfield and Pritchard, 2013), multi-criteria decision making (Ramezani et al. 2013) and sample average approximation (Lee et al 2010) have also been proposed as suitable approaches for solving CLSCM problems. Compared to the number of research papers involving exact and analytical methods, studies that have developed metaheuristics for solving large-scale CLSCM problems are more limited, although they have been increasing over the last few years (Govindan et al 2015).

Given that metaheuristics have been successfully applied to large-scale CLSM problems, we were interested in exploring the potential of using a PSO metaheuristic to solve a non-linear optimisation model that optimises location-allocation and pricing-inventory decisions. Since its introduction, PSO has undergone numerous refinements and improvements in terms of computational efficiency and efficacy in obtaining superior solutions (Lin et al., 2015; Cho et al., 2011; Tsai et al., 2012). In PSO, the search procedure often converges at local optima, thereby limiting its ability to find high-quality and globally optimal solutions (Bonyadi and Michalewicz, 2014). Another issue with PSO is its slow convergence speed, which results in long computational times when solving large-scale optimisation problems. In our study, we aim to address these issues appropriately.

Based on the gaps identified in the literature review, in this paper we focus our efforts on the development of a computationally efficient CLSC network configuration model that 
incorporates representative strategic, tactical and operational decisions. In so doing, we demonstrate the capacity of the proposed model to account for economic and product flow aspects while considering an integrated forward-reverse logistics network.

\section{Problem Definition and Model Development}

In this study, we consider a closed-loop supply chain involving a company that is launching a new product in a certain market (see Figure 2). The company has to make certain decisions related to the configuration of its supply chain network for the new product. These decisions include the location of retailers, assignment of customer zones to each retailer, determination of inventory cycles, and pricing decisions.

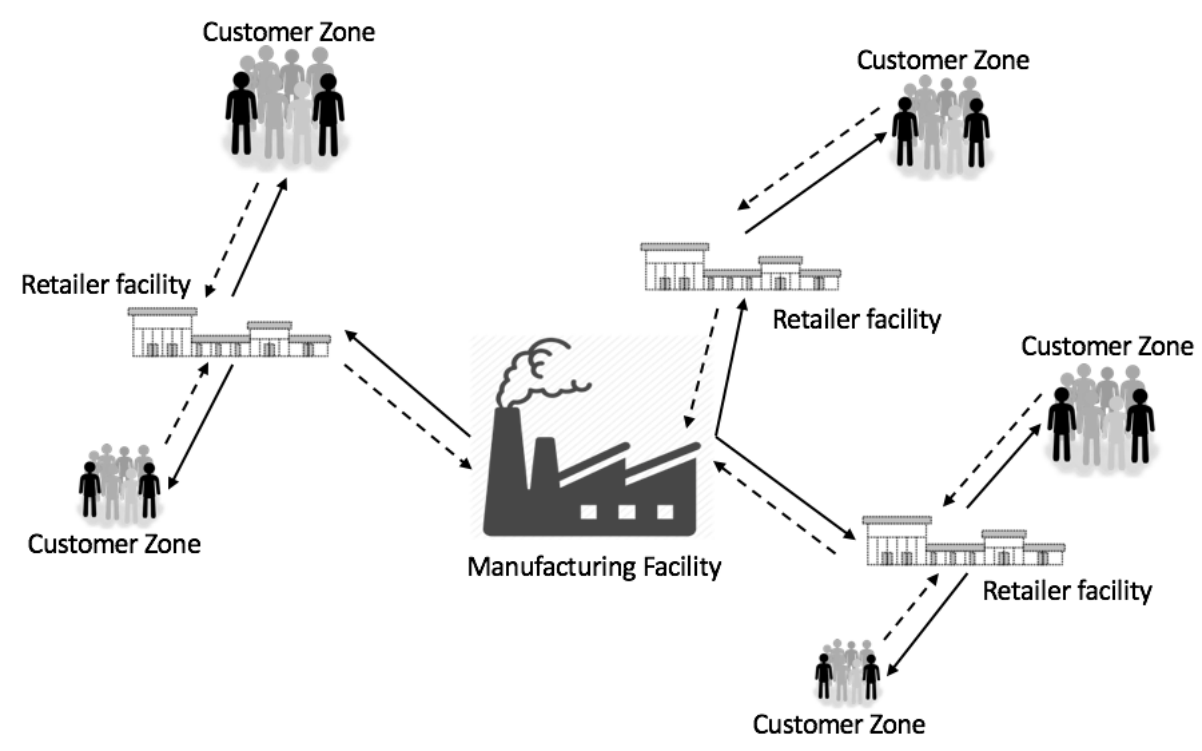

Fig. 2. Generic closed-loop supply chain model considered in this study

Following the approach adopted by Kaya and Uerk (2016), we consider that the company first identifies $N$ different customer zones in its target market. Constrained by its financial capacity, the company decides to establish $M$ number of retailers in the market to sell their product. Since we are considering an integrated CLSC, we assume that these retailers will also act as collection centres for returned products (Savaskan et al., 2004). The supply chain issues that we look to address in this exercise are all inter-related and, therefore, the goal is to obtain the optimal overall outcome, given the multiple aspects considered. Figure 2 illustrates the generic model of the closed-loop supply chain that we are considering in this study. We assume that there is a manufacturer and that the used products collected at retailers will be sent back to the manufacturer for remanufacturing. We assume that there are no existing compatible retailers and, hence, we have to optimally locate all the new retailers while considering transportation distances. We use overall distance as the objective function $\left(Z_{1}\right)$ when solving the locationallocation problem (LAP) using IPSO. In the next part of the formulation, we consider overall profit as the objective function $\left(Z_{2}\right)$ when solving the pricing-inventory problem (PIP) using a gradient descent method. Mathematically, $Z_{1}$, used for locating the retailer facilities, is found by minimising: 


$$
\begin{gathered}
Z_{1}=\left(a_{1} \times \sum_{j=1}^{M} y_{j} \times \operatorname{dist}(\text { Manufacturing Facility, Retailer Facility })_{j}\right)+a_{2} \times \\
\left.\sum_{i=1}^{N} \sum_{j=1}^{M} x_{i j} \times \operatorname{dist}\left(\text { Retailer Facility }_{j}, \text { Customer Zone }_{i}\right)\right)
\end{gathered}
$$

Subject to:

$$
\begin{array}{ll}
\sum_{j} x_{i j}=1 & \forall i \\
x_{i j} \leq y_{j} & \forall i, j
\end{array}
$$

Here, $a_{1}$ and $a_{2}$ are weights assigned according to the influence of the respective terms on the final profits of the company. The first term in Eqn. 1 represents the overall distance between the manufacturer and retailers. The second term in Eqn. 1 represents the overall distance between the retailer facilities and customer zones. In this formulation (Eqn. 1), $x_{i j}$ and $y_{j}$ are the decision variables; $x_{i j}$ indicates whether customer zone $i$ is served by retailer $j$.

$$
x_{i j}=\left\{\begin{array}{cc}
1 & \text { if customers from zone } i \text { are served by retailer } j \\
0 & \text { otherwise }
\end{array}\right.
$$

We also define another binary variable, $y_{j}$, which denotes whether retailer $j$ is established or not, as given below:

$$
y_{j}=\left\{\begin{array}{cc}
1 & \text { if retailer } j \text { is established } \\
0 & \text { otherwise }
\end{array}\right.
$$

The company has to set a market price for selling the new product, which will be an important factor in determining the volumes sold. Apart from the unit production cost, the cost that the company incurs in RL - the rebate cost - also needs to be considered in developing an overall optimal pricing policy. Moreover, the inventory cycle times across the supply chain have to be considered in reaching an optimal pricing decision.

In our model, ' $c$ ' denotes the unit production cost of the new product, ' $p$ ' denotes the selling price, ' $r$ ' denotes the rebate price or the financial incentive (refund) offered for each returned product, and ' $r_{m}$ ' denotes the remanufacturing cost per unit. To simplify our problem, we assume that there is the same level of salvage value for all returned products, although they may not be in the same condition.

Variable ' $\tau_{i}$ ' denotes the number of people in customer zone $i$ who are considered potential buyers of the new product. We assume that the customers go to the retailer locations by themselves to buy the product, and that the demand for the product is price and accessibility sensitive. That is, if the product has a lower price and the retailer is nearer to the customer zone, then the demand is more likely to be higher. We express the demand mathematically as $D_{i j}=$ $\tau_{i} e^{-k p} x_{i j} \alpha_{i j}$, where ' $D_{i j}$ ' denotes the demand directed from customer zone $i$ to retailer $j$, where $k$ is the coefficient of the price sensitivity of demand, and $\alpha_{i j}$ is a parameter (between 0 and 1 depending on the distance between zone $i$ and retailer $j$ ) that denotes the proportion of the potential customers who will actually buy the product. Similar to the way that the demand 
variable was introduced, we define a variable that denotes the number of people willing to return the product and mathematically represent it as $R_{i j}=\tau_{i}\left(1-e^{-g r}\right) x_{i j} \beta_{i j}$. Here, $g$ is the incentive sensitivity of the used quantities of products and $\beta_{i j}$ is a parameter (between 0 and 1 depending on the distance between customer zone $i$ and retailer location $j$ ) that denotes the proportion of customers who are willing to return the used product.

Customers can return used products at the retailer outlets. It is assumed that it will be economical for shipments of used/returned products to be sent back to the manufacturer following the arrival of a shipment of new products at the retail outlet. This means that the returned products can be sent back through the same distribution channels so that transportation costs are minimised. Thus, the inventory cycle time, or the inter-arrival time between two shipments, $T_{j}$, is affected by the retailer's collection rate and fixed shipment cost. The complete set of notation used in the mathematical model that represents the inventory and pricing problem is provided in Table 1.

Table 1: Notation used in the inventory and pricing problem model

\begin{tabular}{ll}
\hline Notations & \multicolumn{1}{c}{ Description } \\
\hline$\tau_{i}$ & Parameters \\
$D_{i j}$ & Dember of potential customers in zone $i$ \\
$R_{i j}$ & Number of returned products from zone $i$ to retailer $j$ \\
$s$ & Selling price of a remanufactured unit \\
$c_{r}$ & Remanufacturing cost per unit \\
$c$ & Cost of producing a new product \\
$F_{j}$ & Total cost of establishing and operating retailer $j$ \\
$k$ & Price sensitivity parameter \\
$g$ & Incentive sensitive parameter \\
$A_{j}$ & Ordering cost at retailer $j$ \\
$h_{n j}$ & Unit holding cost of new product at retailer $j$ \\
$h_{r j}$ & Unit holding cost of used product at retailer $j$ \\
$T_{j}$ & Inventory cycle time for retailer $j$ \\
$x_{i j}^{*}$ & Optimum customer zone allocation \\
$y_{j}^{*}$ & Optimum retail outlets \\
$n_{j}$ & Number of customer zones allocated to retailer $j$ \\
\hline & Decision Variables \\
\hline$p$ & Price value offered per product unit (PIP) \\
$r$ & Incentive value offered per used product unit (PIP) \\
$x_{i j}$ & Boolean variable for allocating customer zone $i$ to retailer $j$ (LAP) \\
$y_{j}$ & Boolean variable to indicate whether retailer $j$ is established (LAP) \\
\hline & \\
\hline &
\end{tabular}

Then, we can express the profit function for the company, in terms of the key decision variables ( $p$ and $r$ ), as $Z_{2}$ (Eqn. 4). 
Maximise:

$$
Z_{2}=\left(\begin{array}{c}
\sum_{i} \sum_{j}(p-c) \tau_{i} e^{-k p} x_{i j}^{*} \alpha_{i j}+\sum_{i} \sum_{j}\left(s-c_{r}-r\right) \tau_{i}\left(1-e^{-g r}\right) x_{i j}^{*} \beta_{i j}-\sum_{j} F_{j} y_{j}^{*}- \\
\sum_{j}\left[\frac{A_{j}}{T_{j}}+\left(\sum_{i}\left[\tau_{i} e^{-k p} x_{i j}^{*} \alpha_{i j} T_{j} \frac{h_{n j}}{2}+\tau_{i_{i}}\left(1-e^{-g r}\right) x_{i j}^{*} \beta_{i j} T_{j} \frac{h_{r j}}{2}\right]\right)\right] y_{j}^{*}
\end{array}\right)
$$

where $x_{i j}^{*}$ and $y_{j}^{*}$ represent optimal values obtained after solving $Z_{1}$. The first term $\left(\sum_{i} \sum_{j}(p-c) \tau_{i} e^{-k p} x_{i j} \alpha_{i j}\right)$ in Eqn. 4 represents revenue obtained by selling the product at unit price $p$ when the unit production cost was $c$. The second term $\left(\sum_{i} \sum_{j}\left(s-c_{r}-\right.\right.$ $\left.r) \tau_{i}\left(1-e^{-g r}\right) x_{i j} \beta_{i j}\right)$ represents revenue obtained when a remanufactured product is sold at unit price $s$ while the unit cost of remanufacturing was $c_{r}$ and the rebate offered was $r$ (per unit). The third term represents the cost incurred in establishing retail outlets. The final term $\left(\sum_{j}\left[\frac{A_{j}}{T_{j}}+\left(\sum_{i}\left[\tau_{i} e^{-k p} x_{i j} \alpha_{i j} T_{j} \frac{h_{n j}}{2}+\tau_{i}\left(1-e^{-g r}\right) x_{i j} \beta_{i j} T_{j} \frac{h_{r j}}{2}\right]\right)\right] y_{j}\right)$ represents the inventory holding (for new and remanufactured products) and ordering costs $\left(\frac{A_{j}}{T_{j}}\right)$. In this formulation, decision variables $p$ and $r$ are optimised to maximise profit $\left(Z_{2}\right)$.

\section{Solution Methodology}

The proposed model represents two (sub) problems: a location-allocation problem (LAP, see Eqn. 1), and a pricing-inventory problem (PIP, see Eqn. 4). In the LAP, customer zones are allocated to each of the retailers based on their physical proximities. Once the allocations are made, the pricing (product price and incentive value) and inventory cycle time are optimised, which is referred to here as the PIP. The LAP formulation is similar to that of the basic facility location problem. Since the facility location problem is NP-hard, the proposed problem, including the sub-problems LAP and PIP, is also treated as NP-hard. To solve this problem, we have developed the sequential loop algorithm illustrated in Figure 3. We first solve the LAP part of the model and then, in next step, we resolve the PIP.

To solve the LAP with a fixed number of customer zones and retail locations, we propose a new algorithm called improved particle swarm optimisation (IPSO). IPSO extends the traditional PSO algorithm to incorporate two new features: game theory-based competition among particles, and mutation-based evolution of solutions. These two features are employed to improve the performance of PSO and effectively and efficiently optimise the LAP. A detailed description of the proposed IPSO algorithm is discussed in the following subsections.

\subsection{Improved PSO (IPSO)}

\subsubsection{Particle Swarm Optimisation (PSO)}

In PSO, a swarm of particles are engaged in a search for the best solution to a problem, where each particle represents a possible solution. In the search process, each particle accelerates in the direction of the best solution it has found so far, as well as in the direction of the global best position discovered so far by any of the particles in the swarm. Table 2 presents the notations that are used to describe the workings of PSO. 


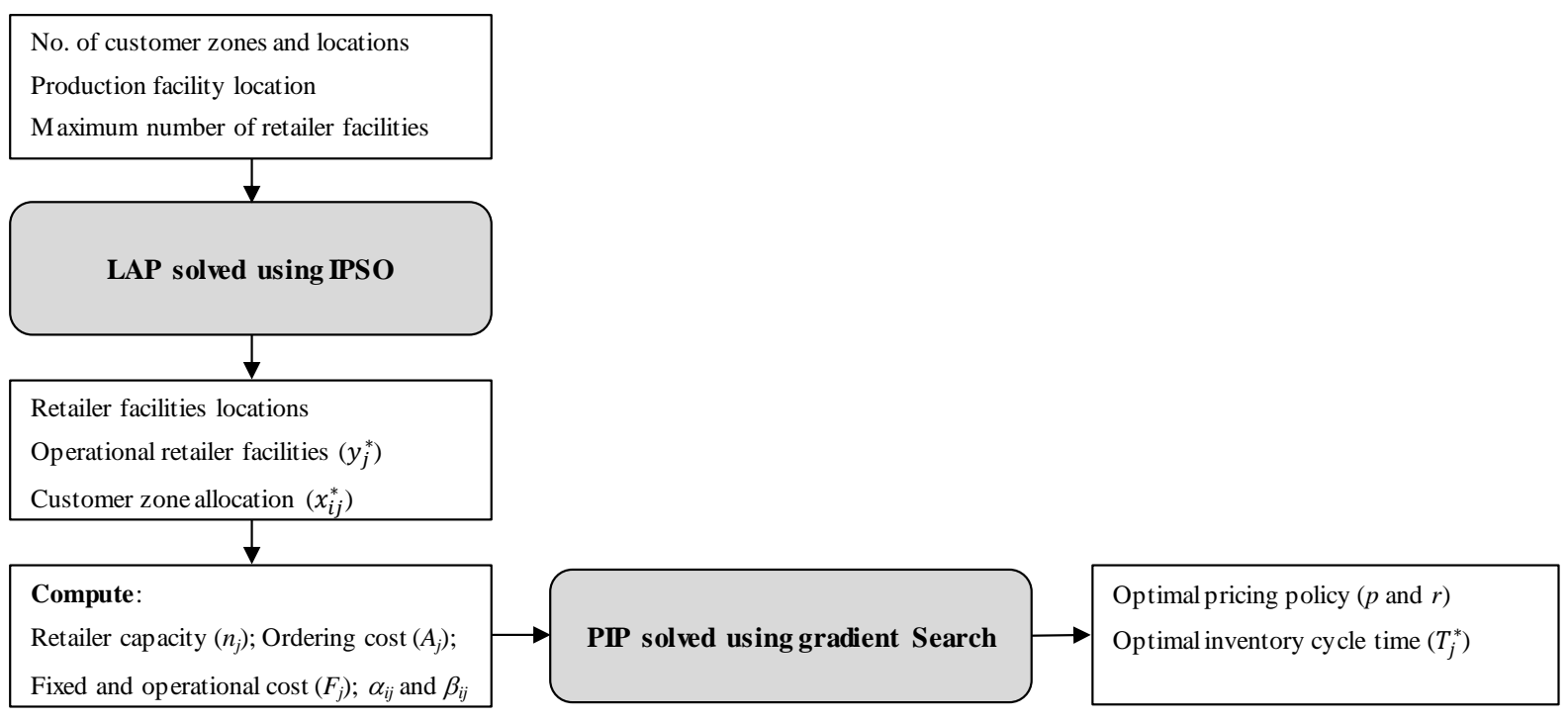

Fig. 3. The overall two-stage solution approach

Table 2: Notations used in the PSO

\begin{tabular}{ll}
\hline Notations & \multicolumn{1}{c}{ Description } \\
\hline Present $_{i}(t)$ & $i^{\text {th }}$ particle's position in iteration $t$ \\
$V_{i}(t)$ & $i^{\text {th }}$ particle's velocity in iteration $t$ \\
pBest $_{i}(t)$ & Personal best position of particle $i$ \\
$g B e s t(t)$ & Global best position of all particles \\
$c_{1}, c_{2}$ & Acceleration coefficients \\
$w$ & Weight coefficient \\
\hline
\end{tabular}

The parameters $\operatorname{Present}_{i}(t)$ and $V_{i}(t)$ are updated in each iteration $t$ using the following equations:

$$
\begin{aligned}
V_{i}(t+1)= & w \times V_{i}(t)+c_{1} \times \operatorname{rand}(0,1) \times\left[\operatorname{pBest}_{i}(t)-\operatorname{Present}_{i}(t)\right]+ \\
& c_{2} \times \operatorname{rand}(0,1) \times\left[\operatorname{gBest}(t)-\operatorname{Present}_{i}(t)\right] \\
& \operatorname{Present}_{i}(t+1)=\operatorname{Present}_{i}(t)+V_{i}(t+1)
\end{aligned}
$$

where $\operatorname{rand}(0,1)$ is a real random number from a uniform random number between $(0,1)$, and $w$ is the weight coefficient, which varies between $(0.1,0.9)$. The parameter $p B e s t_{i}$ is updated according to Eq. (9):

$$
\text { pBest }_{i}(t+1)=\left\{\begin{array}{cl}
\operatorname{pBest}_{i}(t) & \text { if } f\left(\operatorname{Present}_{i}(t+1)\right) \leq f\left(p \operatorname{Best}_{i}(t)\right) \\
\operatorname{Present}_{i}(t+1) & \text { if } f\left(\operatorname{Present}_{i}(t+1)\right)>f\left(p \operatorname{Best}_{i}(t)\right)
\end{array}\right.
$$

Then, gBest, which is the best position among all particles in the swarm during all previous steps, is updated using Eq. (10). 


$$
g B \operatorname{est}(t+1)=\arg \left(\max \left(f\left(p \operatorname{Best}_{i}(t+1)\right)\right)\right.
$$

The value of $V$ can be limited to the range $\left[-V_{\max }, V_{\min }\right]$ to ensure that the particles move within the search space.

In this paper, variable $w$ is the inertia weight, and its value is typically varied in each step as the particles converge towards the optimal solution.

In PSO, particles often converge prematurely at local optima, which limits the search process in finding the optimal solution in the search space. This phenomenon is generally referred as premature convergence (Clerc and Kennedy, 2002). This is one of the limitations of PSO that we seek to address through an improved PSO algorithm. The following section details the proposed mechanism, which utilises mutations to avoid premature convergence.

\subsubsection{Adaptive PSO with Mutation}

Experiments demonstrate that in PSO, there is a lack of population diversity of particles at the premature and global convergences. That is, particles will accumulate at the local or global optima, respectively. More often than not, the lack of population diversity leads to premature convergence. To avoid this problem in PSO, we propose the concept of mutation to diversify the population after a certain condition is met. Table 3 presents the notation that is used to describe the workings of IPSO.

Table 3: Notation used in IPSO

\begin{tabular}{ll}
\hline Notations & \multicolumn{1}{c}{ Description } \\
\hline$D(t)$ & Population diversity at the $t^{\text {th }}$ iteration \\
$D$ & Population diversity triggering parameter for mutation \\
$L$ & Diagonal length of the search space \\
$S$ & Size of the swarm \\
$D i m$ & Dimension of the solution space \\
$P_{i d}$ & Coordinate value of the $d^{\text {th }}$ dimension of the $i^{\text {th }}$ particle \\
$p_{d}$ & Average value of the $d^{\text {th }}$ dimension coordinate \\
$f R a t e(t)$ & Relative rate of change of value of objective function $Z_{l}$ \\
$w^{\prime}$ & Adaptive inertial weight \\
$c$ count & No. of consecutive generations with unchanged cost \\
$C$ & Triggering parameter for count \\
$p_{m}$ & Probability of mutation \\
$m$ & Number of particles considered for mutation \\
\hline
\end{tabular}

We define a parameter, $D(t)$, called the population average distance amongst points, to describe the population diversity (Krink et al., 2002), which can be mathematically expressed as:

$$
D(t)=\frac{1}{S L} \sum_{i=1}^{S} \sqrt{\sum_{d=1}^{D i m}\left(P_{i d}(t)-p_{d}\right)^{2}}
$$


The swarm average particle distance describes the distribution of the particles. Smaller values of $D(t)$ indicate that the particles are concentrated closely in the search space.

We define ' $P_{i d}$ ' to represent a 2-D array, where ' $i$ ' denotes the particle number (row number) and ' $d$ ' denotes the value of that dimension (column number). One single row (one particle) will have the coordinates of all the retailers. We define another variable, 'count', which denotes the number of consecutive generations in which the optimal cost value remains the same. We also define a variable, fRate, which represents the relative rate of change in the value of the objective function $Z_{1}$ (Eq. 1; Lin and Hua, 2009). Mathematically,

$$
\text { fRate }(t)=\frac{\left|Z_{1}(t)-Z_{1}(t-T)\right|}{\left|Z_{1}(t-T)\right|}
$$

where $Z_{1}(t)$ is the best objective function value found among the swarm particles in generation $t$, and $T$ is a fixed number of generations. Now, we try to determine the value of inertial weight $w$, which is adjusted according to the value of fRate.

$$
w^{\prime}= \begin{cases}\alpha_{1}+\frac{\operatorname{rand}(0,1)}{2}, & \text { fRate } \geq 0.05 \\ \alpha_{2}+\frac{\operatorname{rand}(0,1)}{2}, & \text { fRate }<0.05\end{cases}
$$

where $\operatorname{rand}(0,1)$ is any random number from the uniform distribution. When fRate $\geq 0.05$, it suggests that the relative rate of change of the objective function value is higher, which implies that the swarm is still in the exploration stage. Therefore, having a higher value of inertial weight $w$ is of benefit to the algorithm search process. Similarly, when fRate $<0.05$, a smaller value of inertial weight $w$ is used in the algorithm. Thus, $\alpha_{1}>\alpha_{2}$. Experiments suggest that the values of $\alpha_{1}$ and $\alpha_{2}$ should be approximately 0.6 and 0.2 , respectively (Lin and Hua, 2009).

Until the $T^{\text {th }}$ iteration, we allow the algorithm to follow the traditional PSO technique so that the population starts converging to one of the local optima. Then from the $T+1^{\text {th }}$ iteration, the mutation rule is applied. When the value of $D(t)$ falls below a certain specified value ' $D$ ', or when there is no significant change in the value of fitness in successive generations (for many generations (count) $\geq 15$ ), the mutation operation is triggered, which is designed to diversify the population so that it leaves the local optima and explores the remaining search space. We assume the mutation probability ' $p_{m}$ ' to take values in the interval $[0.1,0.3]$ and that mutation only takes place in $m$ number of particles. We generate random numbers $\operatorname{rand}_{i}(0,1)(i=$ $1,2 \ldots m)$ and produce a new mutated particle $P_{i d}(t+1)$, if $\operatorname{rand}_{i}(0,1)<p_{m}$, given as

$$
P_{i d}(t+1)=P_{i d}(t) \times\left(1+0.5 \times \operatorname{rand}_{i}(0,1)\right)
$$

\subsubsection{Replicator dynamics}


Another challenge with the traditional PSO algorithm is its slow convergence to the global optimum solution. Thus, a new strategy based on replicator dynamics is incorporated into the proposed IPSO algorithm to address this challenge. We map an analogy between the evolutionary game and the PSO algorithm to operationalise the concept of replicator dynamics.

The replicator dynamics equation allows the objective function value of the particles to incorporate the distribution of particle types (within the swarm). It is an important property as it enables the replicator equation to better imitate the selection process. The general form of the evolutionary game consists of three key components: players, strategy space and the payoff function. Players can choose a strategy out of the available set of strategies and receive an associated payoff value. Using the payoff values (objective function value) for different strategies, we can calculate the rate of proportion change of the opted strategies. When the game reaches equilibrium, it has reached an evolutionarily stable strategy which is the optimal strategy set for all the players of the game. In IPSO, particles represent players in a game, the search space is represented as a strategy space, velocity represents the rate of proportion change, the objective function represents the payoff function and gBest represents the evolutionarily stable strategy. This approach is illustrated in Figure 4.

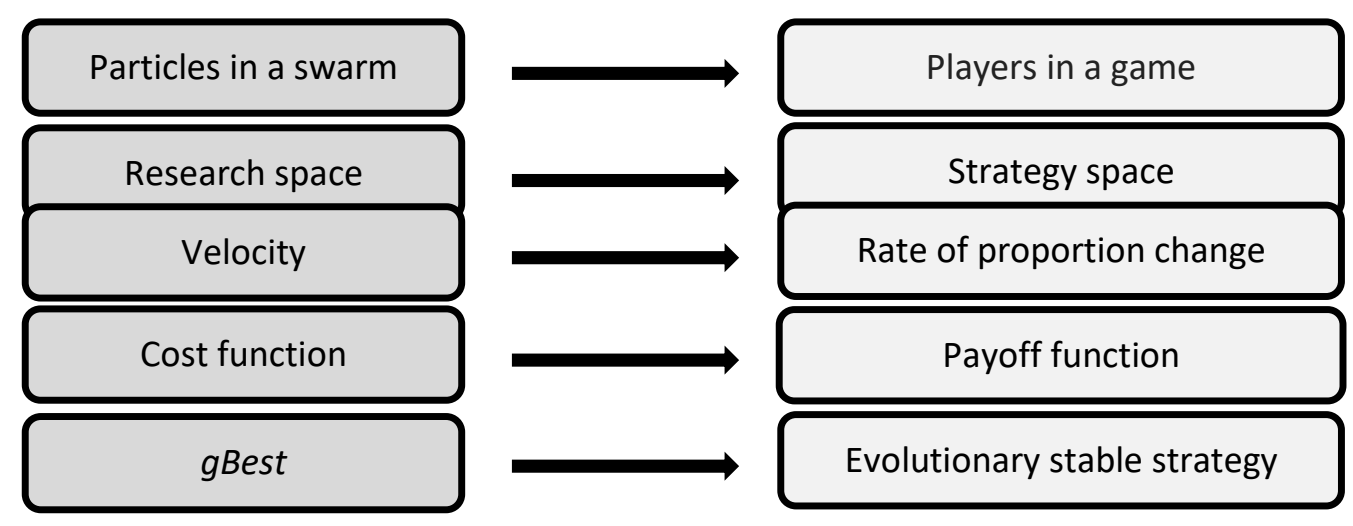

Fig. 4. Logical mapping of PSO on replicator dynamics

As the proportion of particles in the swarm evolves in an iteration of the evolutionary game, we update the velocities of the particles to move them towards positions with higher payoff values. This is done after velocities are updated in PSO. We update the velocities using Eq. (14), which is known as the replicator equation.

$$
\begin{gathered}
\frac{d P_{i d}(t+1)}{d t}=V_{i d}(t+1)=\frac{a}{b+f(t+1)-f(t)} \times V_{i d}(t) \\
P_{i d}(t+1)=P_{i d}(t+1)+V_{i d}(t+1)
\end{gathered}
$$

where ' $a$ ' and ' $b$ ' are constants given appropriate values based on experiments. We assume their values to be 0.001 and 1 , respectively. This refines the search process even more and, hence, the convergence is met earlier. The particle positions are then updated according to Eq. (15). The steps of the proposed IPSO algorithm are illustrated in Figure 5. 


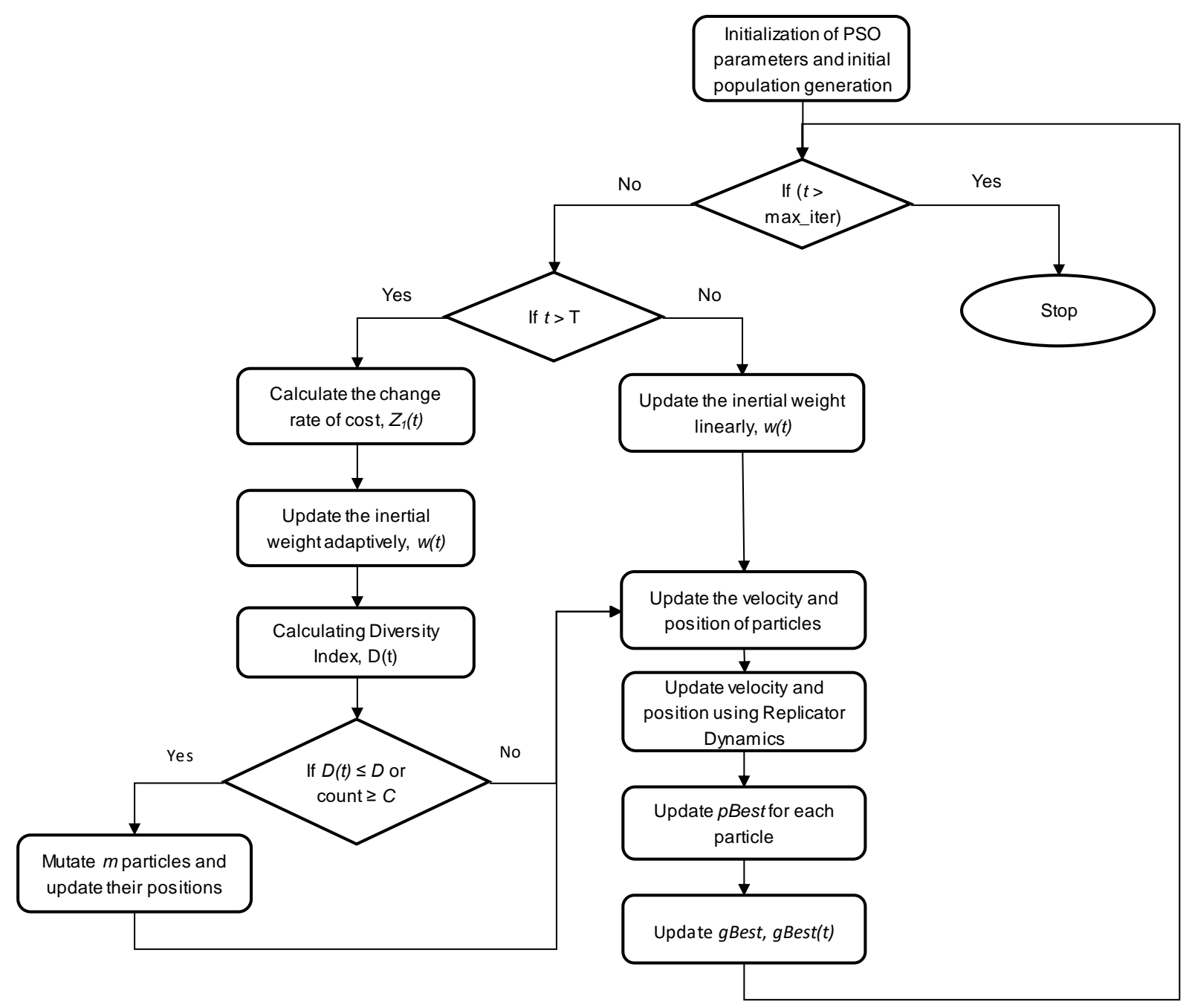

Fig. 5. Flowchart of the IPSO algorithm

The location-allocation problem (LAP) is resolved using the above-mentioned IPSO algorithm. We run a sufficient number of iterations or function evaluations until the algorithm reaches the point of saturation. Next, a gradient search procedure is employed to solve the PIP problem.

\subsection{Gradient descent for the pricing and inventory problem (PIP)}

The location and allocation result from IPSO is utilised in the optimisation of the inventory and pricing model. We first focus on the inventory decisions in the PIP model $\left(Z_{2}\right)$ and observe that the decision variable $T_{j}$ can be expressed in terms of the decision variables $p$ and $r$, which are obtained from the standard economic order quantity (EOQ) model in the inventory theory, as stated in the following proposition.

Proposition 1: If a retailer is opened, i.e. if $y_{j}=1$, then the optimal cycle time between inventory replenishments at this retailer $\left(T_{j}^{*}\right)$, as given by the standard EOQ model, is: 


$$
T_{j}^{*}=\sqrt{\frac{2 A_{j}}{\sum_{i}\left[N_{i} e^{-k p} x_{i j}^{*} \alpha_{i j} h n_{j}+N_{i}\left(1-e^{-g r}\right) x_{i j}^{*} \beta_{i j} h r_{j}\right]}}
$$

We omit the proof for the above proposition since it is a straightforward EOQ result. After substituting the value of $T_{j}^{*}$ in Eq. (4), we get:

Maximise:

$$
\begin{gathered}
Z_{2}=\left(\sum_{i} \sum_{j}(p-c) \tau_{i} e^{-k p} x_{i j}^{*} \alpha_{i j}+\sum_{i} \sum_{j}\left(s-c_{r}-r\right) \tau_{i}\left(1-e^{-g r}\right) x_{i j}^{*} \beta_{i j}-\sum_{j} F_{j} y_{j}^{*}-\right. \\
\left.\sum_{j} \sqrt{2 A_{j}\left(\sum_{i}\left[\tau_{i} e^{-k p} x_{i j}^{*} \alpha_{i j} h n_{j}+\tau_{i}\left(1-e^{-g r}\right) x_{i j}^{*} \beta_{i j} h r_{j}\right]\right)} \cdot y_{j}^{*}\right)
\end{gathered}
$$

This model is solved using the gradient search method to obtain the optimal pricing for new and returned products and the inventory replenishment times.

\section{Numerical Evaluation}

In this section, we analyse the performance of this model using the numerical datasets adopted from Solomon (1987), with particular focus on the proposed algorithm in terms of solution quality and computation time. All of the runs throughout the computational experiments were performed on a workstation with an Intel ${ }^{\circledR}$ Core $^{\mathrm{TM}} \mathrm{i} 7$ processor running at $3.10 \mathrm{GHz}$ and 16 GB of RAM.

\subsection{Data generation}

We have considered a situation where the total number of customer zones $(N)$ is 100 and the company has enough resources to establish 10 retailers $(M)$ to cater to the target market. The coordinates of the customer zones were taken from the benchmark dataset $R C 201100$ proposed in Solomon (1987). The customer zones and the manufacturer are located on a $100 \times 1002-\mathrm{D}$ plane which is considered a scaled version of the real market. Although our aim was to use real-world data for the parameters in our model, it was not possible to determine the exact values for some of the parameters. Therefore, we made realistic assumptions about the values of some parameters, as detailed below.

We consider a proportion of the total population in each customer zone and generate the potential customer population number $\tau_{i}$ for the $i^{\text {th }}$ customer zone, such that $1000<\tau_{i}<5000$. We consider $\alpha_{i j}$ to be a decreasing function of the distance between customer zone $i$ and retailer $j$, represented as $d_{i j}$, such that $\alpha_{i j}=1 /\left(1+d_{i j}\right)$. Similarly, for the return coefficient $\beta_{i j}$, we assume that half of the sales are returned as used products, such that $\beta_{i j}=0.5 \times \alpha_{i j}$. The fixed ordering cost for different retailers is determined once the locations of retailers are established and customer zones have been allocated to those retailers. In effect, retailers which have a larger number of allocated customer zones can benefit from lower ordering costs due to economies of scale, and vice versa. The establishment and operating costs of the retailers are also determined after the allocation of customer zones is finalised, as the capacity of the retailer will depend on the potential demand on that retailer. The unit production cost $c$ is assumed to 
be 100 and the minimum selling price of any re-manufactured product that the company can offer, $s$, is assumed to be 60 . The cost of remanufacturing is taken as $c_{r}=20$. We consider the holding costs $h n_{j}$ and $h r_{j}$ to take random values within $2 \%$ of $c$ and $s$, respectively. The pricesensitive parameter $k$ is assumed to be 0.05 and the incentive-sensitive parameter is assumed to be 0.005 .

In addition to the base case considered above, we take different datasets with varying customer locations and numbers of customer zones from Solomon (1987) to analyse the model for small, medium- and large-sized problem instances.

\subsection{Results}

For the case with $N=100$ and $M=10$, we applied the IPSO algorithm for LAP. The retail location identified by IPSO is illustrated in Fig. 6. It is evident from the data presented in Fig. 6 that the algorithm can effectively place retailers in the customer zones with clustered and uniformly distributed locations.

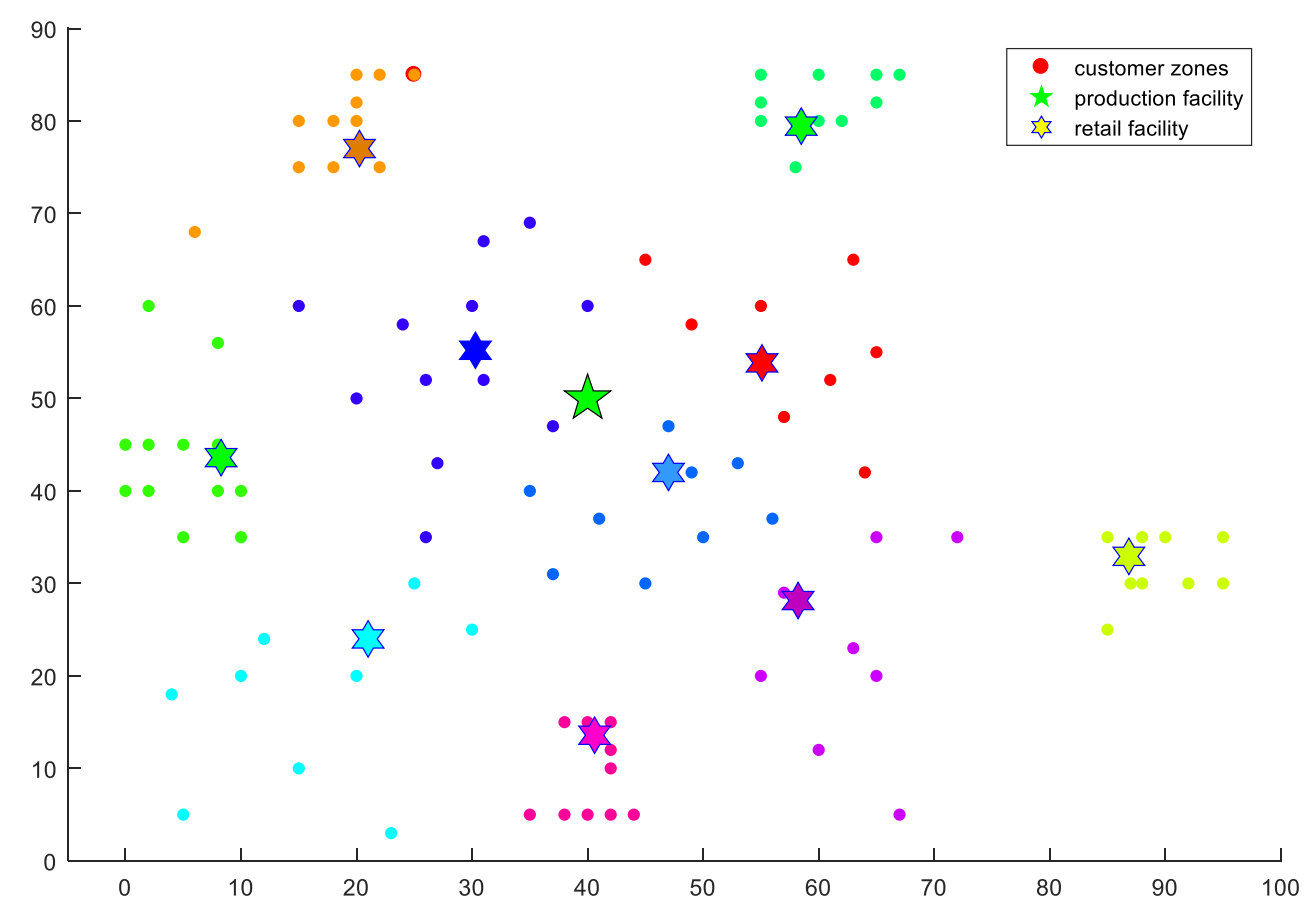

Fig. 6. Plot showing the optimal retailer locations for a given set of customer zones, retailers and manufacturer (RC201100 dataset)

In the case of LAP, our objective function was to minimise the transportation costs, which are directly proportional to the distances between the customer zones, retailers and the manufacturer. As such, we have defined our objective function as a measure of the distance between: (i) manufacturer and retailers, and (ii) retailers and customer zones. In IPSO, our objective is to minimise the total distance between the nodes concerned. Figure 7 illustrates the 
convergence of this objective function with respect to the number of iterations. It can be seen that the IPSO algorithm converges to an optimal solution at around 200 iterations.

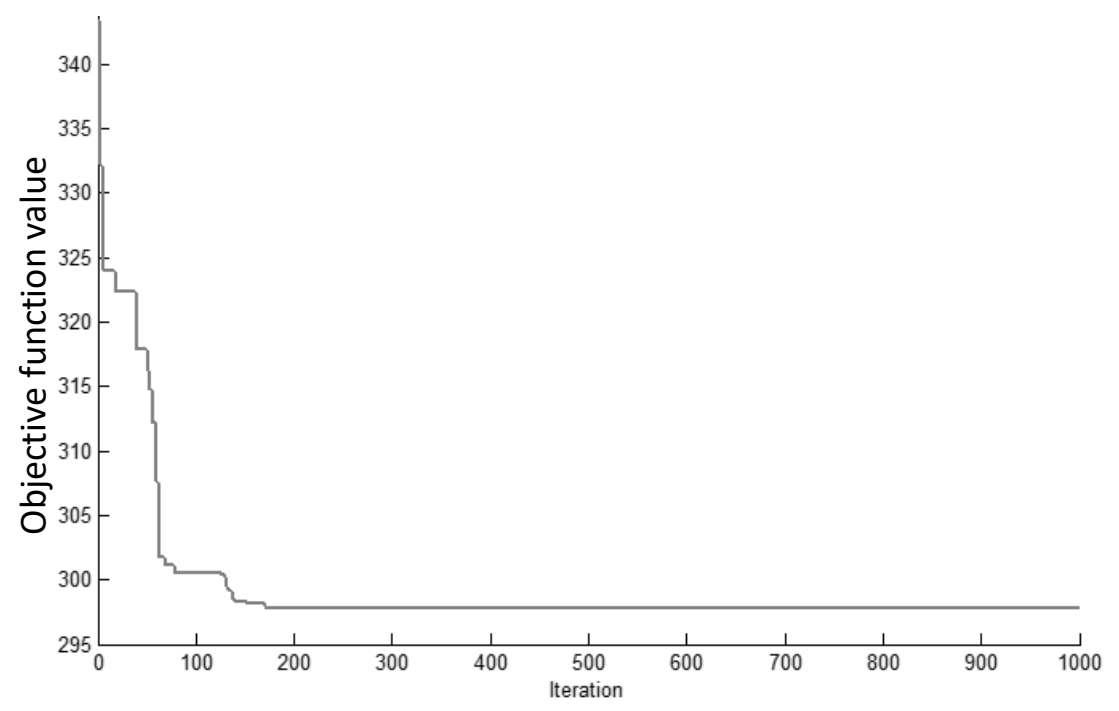

Fig. 7. Performance of IPSO

From the results obtained in IPSO after solving LAP, we know the schema for allocating customer zones to retailers; hence, we know the population count that the retailer is going to be serving. Once we have developed a basic understanding of the scale of the operations based on these results, we can also estimate the capacity of the retailer, their establishment and operational costs, and the fixed ordering cost from the retailer. Equations (19) and (20) give an estimate of the ordering cost $\left(A_{j}\right)$ and operational cost $\left(F_{j}\right)$.

$$
\begin{gathered}
A_{j}=b_{1}+b_{2} \times n_{j} \\
F_{j}=c_{1} \times n_{j}+c_{2} \times\left[\sum_{i=1}^{N}\left(D_{i j}+R_{i j}\right)\right]
\end{gathered}
$$

where $n_{j}\left(=\sum_{i=1}^{N} x_{i j}\right)$ is the number of customer zones allocated to or serviced by retailer $j$. Table 4 represents the allocation schema for the retailers, and the ordering cost and total operational cost of the retailers, which we use in the numerical example. For the values calculated in Table 4, we have assumed that $b_{1}=1000, b_{2}=100, c_{1}=100$ and $c_{2}=2$.

We then proceed to solve the pricing and inventory problem and apply the gradient search method to obtain the optimal pricing policy. In the PIP model, we applied the gradient descent algorithm using the values of $A_{j}$ and $F_{j}$ to obtain an optimal pricing policy, including the optimal selling price ' $p$ ' of a new unit and the incentive ' $r$ ' that the company will pay to the customer for each returned product. For the numerical example considered, the optimal values for the prices are $p=126.26$ and $r=19.22$. So, the optimal profit that the company should settle on is 26.26 per new unit and 25.78 for a re-manufactured unit (i.e. $s-r-c_{r}$, where $c_{r}$ is realistically assumed to be 15). The optimised values of $p$ and $r$ after solving PIP are the same for all the retail facilities. 
Table 4: Number of allocations, ordering prices and operational costs of retailers

\begin{tabular}{cccc}
\hline $\begin{array}{c}\text { Retailer number } \\
(j)\end{array}$ & $\begin{array}{c}\text { Number of customer } \\
\text { zones allocated }\left(n_{j}\right)\end{array}$ & $\begin{array}{c}\text { Ordering price } \\
\left(A_{j}\right)\end{array}$ & $\begin{array}{c}\text { Operational cost } \\
\left(F_{j}\right)\end{array}$ \\
\hline 1 & 11 & 2100 & 5726.89 \\
2 & 12 & 2200 & 5257.30 \\
3 & 8 & 1800 & 4337.21 \\
4 & 12 & 2200 & 6664.63 \\
5 & 8 & 1800 & 4590.43 \\
6 & 11 & 2100 & 6414.34 \\
7 & 10 & 2000 & 3991.11 \\
8 & 9 & 1900 & 6358.45 \\
9 & 10 & 2000 & 6295.79 \\
10 & 9 & 1900 & 5089.11 \\
\hline
\end{tabular}

After determining the optimal selling and return prices, we then calculate the optimal inventory cycle time of the facilities $\left(T_{j}\right)$. Table 5 presents the optimal inventory cycle times for each retailer.

Table 5. Optimal inventory cycle time

\begin{tabular}{cc}
\hline Retailer number $(j)$ & $\begin{array}{c}\text { Inventory cycle time } \\
\left(T_{j}^{*}, \text { days }\right)\end{array}$ \\
\hline 1 & 2.52 \\
2 & 2.74 \\
3 & 2.99 \\
4 & 3.80 \\
5 & 12.37 \\
6 & 4.02 \\
7 & 4.87 \\
8 & 5.18 \\
9 & 3.61 \\
10 & 2.51 \\
\hline
\end{tabular}

\subsection{Performance comparison of IPSO on small, medium and large problem instances}

The performance of IPSO is compared against standard metaheuristics such as PSO, GA and SA. The datasets from Solomon (1987) were adapted to generate CLSCM problem instances with 25, 50 and 100 customer zones. The stopping criterion for the metaheuristics was set to 100,000 objective function evaluations for all instances. It was assumed that a maximum of 10 
retailers can be opened for all problem instances. The best solution obtained by applying IPSO and the above-mentioned metaheuristics is detailed in Table 6. It can be seen that there is an improvement of $17.56 \%$ (on average) in the objective function value for LAP when IPSO is used on all the problem instances. In all the instances, IPSO obtained better solutions than SA, GA and PSO.

Table 6. Performance comparison for IPSO, PSO, GA and SA on test instances (where Clust: clustered, Rand: random)

\begin{tabular}{|c|c|c|c|c|c|c|c|}
\hline Dataset & Type & $\begin{array}{c}\text { Customer } \\
\text { zones }\end{array}$ & SA & GA & PSO & IPSO & $\begin{array}{c}\text { Improvement } \\
\text { (\%) }\end{array}$ \\
\hline C10125 & Clust & 25 & 258.92 & 223.75 & 217.36 & 201.53 & $22.17 \%$ \\
\hline C10150 & Clust & 50 & 563.33 & 501.15 & 481.31 & 447.30 & $20.60 \%$ \\
\hline C101100 & Clust & 100 & 1494.85 & 1307.91 & 1304.60 & 1190.40 & $20.37 \%$ \\
\hline C20125 & Clust & 25 & 301.74 & 260.34 & 259.20 & 229.10 & $24.07 \%$ \\
\hline C20150 & Clust & 50 & 671.00 & 560.63 & 573.49 & 543.77 & $18.96 \%$ \\
\hline C201100 & Clust & 100 & 1499.60 & 1340.03 & 1322.10 & 1270.80 & $15.26 \%$ \\
\hline R10125 & Rand & 25 & 327.36 & 281.05 & 283.86 & 270.37 & $17.41 \%$ \\
\hline R10150 & Rand & 50 & 753.63 & 635.86 & 619.01 & 611.16 & $18.90 \%$ \\
\hline R101100 & Rand & 100 & 1396.62 & 1183.90 & 1190.12 & 1165.80 & $16.53 \%$ \\
\hline R20125 & Rand & 25 & 325.89 & 300.55 & 288.57 & 269.90 & $17.18 \%$ \\
\hline R20150 & Rand & 50 & 698.44 & 632.91 & 622.57 & 617.34 & $11.61 \%$ \\
\hline R201100 & Rand & 100 & 1382.83 & 1200.31 & 1190.10 & 1172.00 & $15.25 \%$ \\
\hline RC10125 & Rand + Clust & 25 & 378.39 & 344.44 & 333.64 & 320.62 & $15.27 \%$ \\
\hline RC10150 & Rand + Clust & 50 & 877.22 & 759.04 & 747.92 & 722.88 & $17.59 \%$ \\
\hline RC101100 & Rand + Clust & 100 & 1590.88 & 1449.90 & 1451.15 & 1415.80 & $11.01 \%$ \\
\hline RC20125 & Rand + Clust & 25 & 394.52 & 340.65 & 332.33 & 314.32 & $20.33 \%$ \\
\hline RC20150 & Rand + Clust & 50 & 857.85 & 737.02 & 739.02 & 715.18 & $16.63 \%$ \\
\hline RC201100 & Rand + Clust & 100 & 1698.34 & 1485.16 & 1482.10 & 1410.60 & $16.94 \%$ \\
\hline
\end{tabular}

The algorithmic parameters used for running GA were: population of 50 chromosomes, crossover probability of 0.8 , mutation probability of 0.2 and selection using the tournament method. In the case of SA, the initial temperature was set to 4000 and the cooling rate was set to 0.02 . In the case of PSO, $c_{1}=2, c_{2}=2, w=1$ and $V_{\max }=10$. The parameter settings for IPSO are shown in Table 7.

Table 7. Parameter settings for the IPSO algorithm

\begin{tabular}{cc} 
Parameter & Value \\
\hline$D$ & $10^{5}$ \\
$L$ & $100 \sqrt{2}$ \\
\hline
\end{tabular}




\begin{tabular}{cc}
\hline$S$ & 200 \\
$C$ & 5 \\
$\alpha_{1}$ & 0.6 \\
$\alpha_{2}$ & 0.2 \\
$m$ & 20 \\
$p_{m}$ & 0.3 \\
\hline
\end{tabular}

\section{Conclusions}

Building on the most recent work undertaken in the area of CLSCM, this paper developed a CLSC network configuration model aimed at addressing several research gaps identified in the extant literature. The proposed model can be used to aid location-allocation decisions and pricing-inventory decisions in a two-step process. In the first step, travel distances between customer zones, retailers and a manufacturer are minimised to set up a cost-effective distribution network for shipping new products and taking back returned products. Considering the challenges associated with this decision situation, we developed an improved particle swarm optimisation algorithm which effectively and efficiently searches for the best solution to the location-allocation problem. In the second step, using the results generated in the first step, the optimal selling price, returned product buyback price and stock replenishment cycle times are obtained using the gradient search method.

The development of our modelling approach and solution methodology involved careful evaluation of methods proposed in the most relevant literature, then refining and combining selected approaches to enhance solution quality and computational speed. We selected the few most critical aspects (e.g. facility location, pricing and inventory cycle time) of the SCLM problem for incorporation into the model in the form of decision variables, as well as other aspects (e.g. number of locations, capacity, retailers' fixed and operational costs) to be considered as model parameters. This differentiation allowed us to deal with a larger number of decision variables without adding to the computational difficulty faced in the implementation stage. Second, we built additional measures to address the two inherent challenges associated with the PSO algorithm used in the solution methodology; i.e. convergence on local optima and slow convergence rates. These improvements allowed us to handle larger-scale problem instances without compromising the computational efficiency of the proposed algorithm. Third, we tested our model using benchmark studies consisting of both uniformly distributed and clustered customer zones. Tests conducted on problem instances of different scales (by varying the number of customer zones and retailers) confirmed that the proposed IPSO algorithm performs better than traditional PSO, simulated annealing and genetic algorithm approaches. As such, we have made a useful theoretical contribution to solving CLSCM problems through the development of the proposed model.

In terms of contribution to practice, our solution approach can deal with multiple supply network configuration decisions in a rather seamless and/or holistic manner, leading to globally optimal economic outcomes while ensuring a swifter flow of goods across an integrated 
forward and reverse logistics network. Therefore, we believe that the proposed model could serve as a useful tool for solving CSLM problems more comprehensively.

However, there are significant opportunities for extending our model; for example, by incorporating multi-product, multi-period situations and accounting for uncertainty in product returns. Further refinements to the model may also be achieved through incorporation of more appropriate algorithms that account for the realities and challenges associated with solving PIP, as we have not exclusively evaluated the performance of the PIP component of the proposed model in this paper. However, we believe that these extensions and refinements could be incorporated into the proposed model with minimal modifications to its overall structure.

\section{References}

Ahmadzadeh, E., and B. Vahdani. 2017. "A location-inventory-pricing model in a closed loop supply chain network with correlated demands and shortages under a periodic review system." Computers \& Chemical Engineering 101: 148-166.

Akçal1, E., S. Çetinkaya, and H. Üster. 2009. "Network design for reverse and closed-loop supply chains: An annotated bibliography of models and solution approaches." Networks 53 (3): 231-248.

Alumur, S.A., S. Nickel, F. Saldanha-Da-Gama, and V. Verter. 2012. "Multi-period reverse logistics network design." European Journal of Operational Research 220 (1): 67-78.

Amin, S.H., and G. Zhang. 2013. "A multi-objective facility location model for closed-loop supply chain network under uncertain demand and return." Applied Mathematical Modelling 37 (6): 41654176.

Aras, N., and D. Aksen. 2008. "Locating collection centers for distance-and incentive-dependent Bakireturns." International Journal of Production Economics 111 (2): 316-333.

Aras, N., D. Aksen, and A.G. Tanuğur. 2008. "Locating collection centers for incentive-dependent returns under a pick-up policy with capacitated vehicles." European Journal of Operational Research 191 (3): 1223-1240.

Asl-Najafi, J., B. Zahiri, A. Bozorgi-Amiri, and A. Taheri-Moghaddam. 2015. "A dynamic closed-loop location-inventory problem under disruption risk." Computers \& Industrial Engineering 90: 414428.

Atasu, A., M. Sarvary, and L.N. Van Wassenhove. 2008. "Remanufacturing as a marketing strategy." Management science 54 (10): 1731-1746.

Beamon, B.M., and C. Fernandes. 2004. "Supply-chain network configuration for product recovery." Production Planning \& Control 15 (3): 270-281.

Bonyadi, M.R., and Z. Michalewicz. 2014. "A locally convergent rotationally invariant particle swarm optimization algorithm." Swarm intelligence 8 (3): 159-198.

Chatfield, D.C., and A.M. Pritchard. 2013. "Returns and the bullwhip effect." Transportation Research Part E: Logistics and Transportation Review 49 (1): 159-175.

Chen, J.-M., and C.-I. Chang. 2013. "Dynamic pricing for new and remanufactured products in a closedloop supply chain." International Journal of Production Economics 146 (1): 153-160.

Chen, J. 2011. "The impact of sharing customer returns information in a supply chain with and without a buyback policy." European Journal of Operational Research 213 (3): 478-488.

Clerc, M., and J. Kennedy. 2002. "The particle swarm-explosion, stability, and convergence in a multidimensional complex space." IEEE transactions on Evolutionary Computation 6 (1): 58-73.

Dai, Z., and X. Zheng. 2015. "Design of close-loop supply chain network under uncertainty using hybrid genetic algorithm: a fuzzy and chance-constrained programming model." Computers \& Industrial Engineering 88: 444-457.

De Giovanni, P., and G. Zaccour. 2014. "A two-period game of a closed-loop supply chain." European Journal of Operational Research 232 (1): 22-40. 
De La Fuente, M.V., L. Ros, and M. Cardos. 2008. "Integrating forward and reverse supply chains: application to a metal-mechanic company." International Journal of Production Economics 111 (2): 782-792.

Dowlatshahi, S. 2000. "Developing a theory of reverse logistics." Interfaces 30 (3): 143-155.

Dubey, R., A. Gunasekaran, and S.S. Ali. 2015. "Exploring the relationship between leadership, operational practices, institutional pressures and environmental performance: A framework for green supply chain." International Journal of Production Economics 160: 120-132.

Dutta, P., D. Das, F. Schultmann, and M. Fröhling. 2016. "Design and planning of a closed-loop supply chain with three way recovery and buy-back offer." Journal of Cleaner Production 135: 604-619.

Easwaran, G., and H. Üster. 2010. "A closed-loop supply chain network design problem with integrated forward and reverse channel decisions." Iie Transactions 42 (11): 779-792.

Esmaeili, M., G. Allameh, and T. Tajvidi. 2016. "Using game theory for analysing pricing models in closed-loop supply chain from short-and long-term perspectives." International Journal of Production Research 54 (7): 2152-2169.

Faccio, M., A. Persona, F. Sgarbossa, and G. Zanin. 2014. "Sustainable SC through the complete reprocessing of end-of-life products by manufacturers: A traditional versus social responsibility company perspective." European Journal of Operational Research 233 (2): 359-373.

Genc, T.S., and P. De Giovanni. 2017. "Trade-in and save: A two-period closed-loop supply chain game with price and technology dependent returns." International Journal of Production Economics 183: 514-527.

Govindan, K., and H. Soleimani. 2017. "A review of reverse logistics and closed-loop supply chains: a Journal of Cleaner Production focus." Journal of Cleaner Production 142: 371-384.

Govindan, K., H. Soleimani, and D. Kannan. 2015. "Reverse logistics and closed-loop supply chain: A comprehensive review to explore the future." European Journal of Operational Research 240 (3): 603-626.

Guide Jr, V.D.R., and L.N. Van Wassenhove. 2009. "OR FORUM-The evolution of closed-loop supply chain research." Operations research 57 (1): 10-18.

Hong, X., L. Xu, P. Du, and W. Wang. 2015. "Joint advertising, pricing and collection decisions in a closed-loop supply chain." International Journal of Production Economics 167: 12-22.

Jayaraman, V., R.A. Patterson, and E. Rolland. 2003. "The design of reverse distribution networks: models and solution procedures." European Journal of Operational Research 150 (1): 128-149.

Jeihoonian, M., M.K. Zanjani, and M. Gendreau. 2016. "Accelerating Benders decomposition for closed-loop supply chain network design: Case of used durable products with different quality levels." European Journal of Operational Research 251 (3): 830-845.

Jindal, A., and K.S. Sangwan. 2014. "Closed loop supply chain network design and optimisation using fuzzy mixed integer linear programming model." International Journal of Production Research 52 (14): 4156-4173.

Kaya, O., and B. Urek. 2016. "A mixed integer nonlinear programming model and heuristic solutions for location, inventory and pricing decisions in a closed loop supply chain." Computers \& Operations Research 65: 93-103.

Krink, T., J.S. Vesterstrom, and J. Riget. 2002. "Particle swarm optimisation with spatial particle extension." Evolutionary Computation, 2002. CEC'02. Proceedings of the 2002 Congress on.

Kumar, S., and V. Putnam. 2008. "Cradle to cradle: Reverse logistics strategies and opportunities across three industry sectors." International Journal of Production Economics 115 (2): 305-315.

Lee, D.-H., M. Dong, and W. Bian. 2010. "The design of sustainable logistics network under uncertainty." International Journal of Production Economics 128 (1): 159-166.

Lin, M., and Z. Hua. 2009. "Improved PSO algorithm with adaptive inertia weight and mutation." Computer Science and Information Engineering, 2009 WRI World Congress on.

Lin, Q., J. Li, Z. Du, J. Chen, and Z. Ming. 2015. "A novel multi-objective particle swarm optimization with multiple search strategies." European Journal of Operational Research 247 (3): 732-744.

Listeş, O. 2007. "A generic stochastic model for supply-and-return network design." Computers \& Operations Research 34 (2): 417-442.

Liu, W.-B., and X.-J. Wang. 2008. "An evolutionary game based particle swarm optimization algorithm." Journal of Computational and Applied Mathematics 214 (1): 30-35. 
Lu, Z., and N. Bostel. 2007. "A facility location model for logistics systems including reverse flows: The case of remanufacturing activities." Computers \& Operations Research 34 (2): 299-323.

Maddah, B., and M.Y. Jaber. 2008. "Economic order quantity for items with imperfect quality: revisited." International Journal of Production Economics 112 (2): 808-815.

Meng, K., P. Lou, X. Peng, and V. Prybutok. 2016. "An improved co-evolutionary algorithm for green manufacturing by integration of recovery option selection and disassembly planning for end-of-life products." International Journal of Production Research 54 (18): 5567-5593.

Min, H., H.J. Ko, and C.S. Ko. 2006. "A genetic algorithm approach to developing the multi-echelon reverse logistics network for product returns." Omega 34 (1): 56-69.

Mutha, A., and S. Pokharel. 2009. "Strategic network design for reverse logistics and remanufacturing using new and old product modules." Computers \& Industrial Engineering 56 (1): 334-346.

Nickel, S., F. Saldanha-Da-Gama, and H.-P. Ziegler. 2012. "A multi-stage stochastic supply network design problem with financial decisions and risk management." Omega 40 (5): 511-524.

Parsopoulos, K.E., and M.N. Vrahatis. 2004. "On the computation of all global minimizers through particle swarm optimization." IEEE transactions on Evolutionary Computation 8 (3): 211-224.

Pourhejazy, P., and O.K. Kwon. 2016. "The New Generation of Operations Research Methods in Supply Chain Optimization: A Review." Sustainability 8 (10): 1033.

Ramezani, M., M. Bashiri, and R. Tavakkoli-Moghaddam. 2013. "A new multi-objective stochastic model for a forward/reverse logistic network design with responsiveness and quality level." Applied Mathematical Modelling 37 (1): 328-344.

Salema, M.I.G., A.P. Barbosa-Povoa, and A.Q. Novais. 2007. "An optimization model for the design of a capacitated multi-product reverse logistics network with uncertainty." European Journal of Operational Research 179 (3): 1063-1077.

Salema, M.I.G., A.P. Barbosa-Povoa, and A.Q. Novais. 2010. "Simultaneous design and planning of supply chains with reverse flows: a generic modelling framework." European Journal of Operational Research 203 (2): 336-349.

Savaskan, R.C., S. Bhattacharya, and L.N. Van Wassenhove. 2004. "Closed-loop supply chain models with product remanufacturing." Management science 50 (2): 239-252.

Schweiger, K., and R. Sahamie. 2013. "A hybrid Tabu Search approach for the design of a paper recycling network." Transportation Research Part E: Logistics and Transportation Review 50: 98119.

Shukla, N, and S. Kiridena. 2016. "A fuzzy rough sets-based multi-agent analytics framework for dynamic supply chain configuration" International Journal of Production Research 54(23): 69846996.

Soleimani, H., and G. Kannan. 2015. "A hybrid particle swarm optimization and genetic algorithm for closed-loop supply chain network design in large-scale networks." Applied Mathematical Modelling 39 (14): 3990-4012.

Soleimani, H., M. Seyyed-Esfahani, and G. Kannan. 2014. "Incorporating risk measures in closed-loop supply chain network design." International Journal of Production Research 52 (6): 1843-1867.

Soleimani, H., M. Seyyed-Esfahani, and M.A. Shirazi. 2013. "Designing and planning a multi-echelon multi-period multi-product closed-loop supply chain utilizing genetic algorithm." The International Journal of Advanced Manufacturing Technology 68 (1-4): 917-931.

Solomon, M.M. 1987. "Algorithms for the vehicle routing and scheduling problems with time window constraints." Operations research 35 (2): 254-265.

Souza, G.C. 2013. "Closed-loop supply chains: a critical review, and future research." Decision Sciences 44 (1): 7-38.

Srivastava, S.K. 2008. "Network design for reverse logistics." Omega 36 (4): 535-548.

Tiwari, A., P.-C. Chang, M. Tiwari, and R. Kandhway. 2016. "A Hybrid Territory Defined evolutionary algorithm approach for closed loop green supply chain network design." Computers \& Industrial Engineering 99: 432-447.

Tsai, H.-C., Y.-Y. Tyan, Y.-W. Wu, and Y.-H. Lin. 2012. "Isolated particle swarm optimization with particle migration and global best adoption." Engineering Optimization 44 (12): 1405-1424. 
Vahdani, B., and M. Mohammadi. 2015. "A bi-objective interval-stochastic robust optimization model for designing closed loop supply chain network with multi-priority queuing system." International Journal of Production Economics 170: 67-87.

Zhalechian, M., R. Tavakkoli-Moghaddam, B. Zahiri, and M. Mohammadi. 2016. "Sustainable design of a closed-loop location-routing-inventory supply chain network under mixed uncertainty." Transportation Research Part E: Logistics and Transportation Review 89: 182-214.

Zhu, X., and X. Xiuquan. 2013. "An integrated optimization model of a Closed-Loop Supply Chain under uncertainty." In LISS 2012, 1389-1395. Springer. 